\title{
Cervical rotation, chest deformity and pelvic obliquity in patients with spinal muscular atrophy
}

\author{
Agnieszka Stępień $^{* *}$ D, Łucja Mazurkiewicz², Katarzyna Maślanko ${ }^{3}$, Witold Rekowski ${ }^{1}$ and Maria Jędrzejowska ${ }^{4}$
}

\begin{abstract}
Background: Musculoskeletal disorders are often observed in patients with spinal muscular atrophy (SMA). The aim of the study was to assess passive ranges of rotation in the cervical spine, chest deformity and pelvic obliquity in SMA patients, and to compare these results to the norms obtained in the group of healthy individuals. The second aim was to review these measurements and Cobb angle values for correlations in SMA patients.

Methods: The study included 74 patients with SMA and 89 healthy individuals aged 2 to 18 years. Cervical Rotation (CR), Supine Angle of Trunk Rotation (SATR) and Pelvic Obliquity (PO) tests were carried out.

Results: Cervical rotation ranges were significantly higher in the control group than in SMA patients $(p<0.05)$. Differences between cervical rotation ranges to the left and to the right were significantly larger in SMA I and SMA II groups than in healthy individuals $(p=0.000)$. Chest asymmetry and pelvic obliquity were bigger in SMA groups than in the control $(p<0.05)$. Significant correlations between cervical rotation measurements, chest deformity, pelvic obliquity and Cobb angle were found in SMA individuals, depending on the type.

Conclusions: The results of the study suggest that CR, SATR and PO tests may assist in the assessment of SMA patients in addition to the radiographic evaluation of the spine. Biomechanical relationships between disorders located in various skeletal structures should be taken into account in the treatment of SMA patients. Special attention should be given to assessing postural parameters in non- sitters and sitters. Treatment of patients with SMA and associated musculoskeletal disorders requires a multi-specialist approach.
\end{abstract}

Keywords: SMA, Cervical rotation, Chest deformity, Pelvic obliquity, Scoliosis, Assessment

\section{Background}

Spinal muscular atrophy (SMA) is a progressive neurodegenerative disease of an autosomal recessive trait of inheritance. In its course, motoneurons of the spinal cord are lost, which leads to the generalized muscle weakness and limited motor function [1-5]. The disease is characterized by great variability of the age of onset (from fetal age to adulthood) and severity of clinical

\footnotetext{
* Correspondence: orthosas@wp.pl

${ }^{1}$ Faculty of Rehabilitation, Józef Piłsudski University of Physical Education, Marymoncka 34, 00-968 Warsaw, Poland

Full list of author information is available at the end of the article
}

symptoms (from lethal to asymptomatic). According the classification various clinical forms are distinguished: patients with prenatal onset (SMA 0, death within weeks), very week children unable to sit unaided (SMA I, the acute form), non-ambulant patients able to sit independently (SMA II, the intermediate form), ambulant patients, who may lose ability to walk (SMA III, mild form)) and ambulant adults (SMA IV,; onset of symptoms in adulthood) [6, 7].

Spinal muscular atrophy may lead to many complications: musculoskeletal (scoliosis, chest deformities, joint contractures, hip dislocation), respiratory (impaired 
cough reflex, respiratory distress), gastrointestinal (gastro-esophageal reflux, swallowing problems, malnutrition or obesity) and many others, depending on the type and stage [8-15].

Scoliosis, defined by the Scoliosis Research Society as a three dimensional deformation of the spine with the Cobb angle at least $10^{\circ}$ [16], occurs most often in SMA I, SMA II patients, as well as in individuals with type III who lost their ability to walk independently $[7,14,16]$.

The spinal deformity is usually accompanied by lateral flexion and rotation of the cervical spine and head, chest deformity and pelvic obliquity [8, 13, 17-20] (Fig. 1a). These musculoskeletal impairments may affect the daily functioning of patients with SMA. An incorrect cervical and head alignment may lead to limitations in cervical spine mobility or difficulties in swallowing [11, 21]. Distortion of the rib cage, associated with scoliosis, contributes to respiratory disorders occurring in SMA patients $[9,10,20,22]$, while pelvic obliquity may affect the ability to maintain balance in a sitting position $[13,17,20]$.

Physiotherapy is an important part of the management of spinal muscular atrophy. Conducting effective physiotherapy is connected with the necessity to assess regular the musculoskeletal system and motor function [22]. It is particularly significant in view of screening programs introduced in some countries and new therapeutic procedures $[6,23,24]$, since the application of new pharmacotherapies in SMA will probably change the whole natural history of the disease and significantly increase the number of patients with a chronic type of the disease.

A radiological examination, recommended at least once a year, is a standard in detecting or confirming skeletal deformities in patients with neuromuscular diseases [22, 25].

So far, no other additional tests have been commonly used in the assessment of the spinal deformities in SMA patients. The Adam's test used in screening to diagnose idiopathic scoliosis [16, 26, 27], cannot be usually used in SMA individuals due to the limited ability to perform a forward bending in the standing or sitting position.

In our study we assessed the cervical spine mobility, chest shape and pelvis position with the use of reliable tests adapted to the functional state of SMA patients: Cervical Rotation test (CR), Supine Angle of Trunk Rotation test (SATR), and Pelvic Obliquity test (PO). The tests, performed with Rippstein's plurimeter (Rippstein, Switzerland) and scoliometer (Orthopedic Systems Inc. OSI 1995), have been originally assessed in previous studies in the group of 30 patients aged 4-15 with type

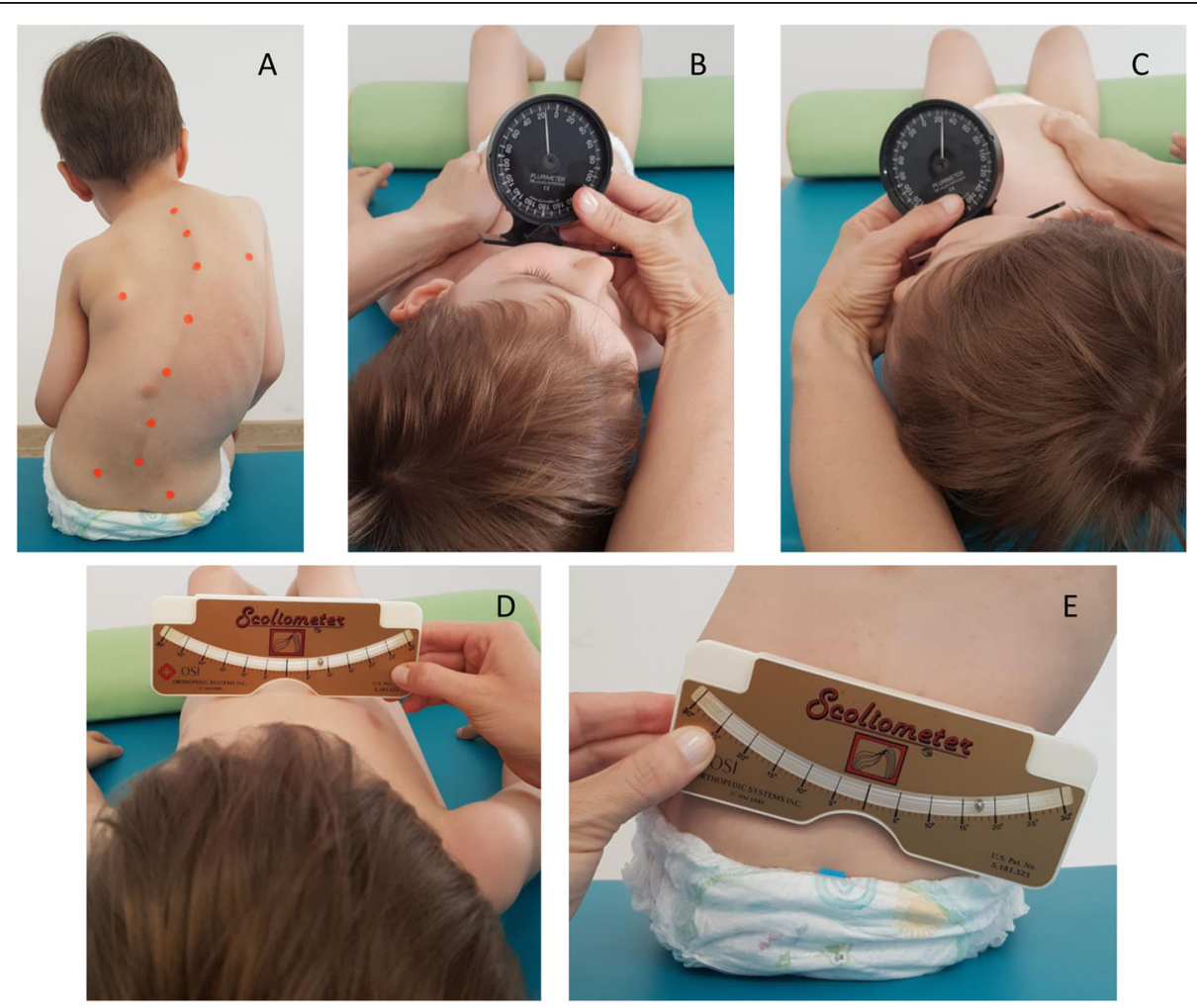

Fig. 1 CR, SATR and PO tests in a boy with type SMA II and scoliosis. Note: a An improper head position, chest deformity and pelvic obliquity in a boy with type SMA II and scoliosis. b Cervical Rotation test to the right, c Cervical Rotation test to the left, $\mathbf{d}$ Supine Angle of Trunk Rotation Lower test, e Pelvic Obliquity test 
II and III SMA. The tests manifested excellent intraobserver and interobserver reliability [28].

The aim of the study was to assess passive ranges of rotation in the cervical spine, chest deformity and pelvic obliquity in SMA patients, and to compare these results to the norms obtained in the group of healthy individuals. The second aim was to review these measurements and Cobb angle values for correlations in SMA patients.

\section{Methods}

The study was conducted after obtaining the acceptance of the Senate Research Ethics Committee at University of Physical Education in Warsaw (SKE 01-03/2016). The protocol was explained to all patients. The legal guardians of the participants gave their written consent to participate in the study.

\section{Subjects}

The study included patients of both sexes aged 2 to 18 with SMA type I, II and III, diagnosed in a genetic examination and not treated pharmacologically. Individuals who underwent scoliosis surgery or tracheostomy, with spine pain or those with scoliosis without an actual $\mathrm{X}$ ray of the spine were not qualified for the study.

Healthy individuals of both sexes aged 2 to 18, without scoliosis and other diseases, were recruited as the control group. The Adam's forward bending test [26] was used as initial assessment qualifying for a control group. Individuals with the value of the angle of trunk rotation at 5 degrees or more were not qualified for the study. Children and adolescents after injuries within the last year or reporting pain in the cervical, thoracic or lumbar spine were also not included in the control group.

\section{Protocol}

The study was conducted during the conference and workshops for SMA patients and their families organized by SMA Foundation and during individual consultations in a physiotherapy centre. The examinations were performed by three physiotherapists familiar with problems of SMA patients. Prior to the study, the physiotherapists had been informed of the study protocol and trained how to perform measurements. The study protocol conducted in SMA and control groups included three tests: Cervical Rotation test, Supine Angle of Trunk Rotation test and Pelvic Obliquity test.

Cervical Rotation test (CR) - the measurement of the range of cervical spine rotation on the left (CR left) and right (CR right) side of the body in a supine position performed with the use of Rippstein's plurimeter (Rippstein, Switzerland), zeroed parallel to the surface and placed on the corpus mandibulae [28] (Fig. 1b, c).

Supine Angle of Trunk Rotation test (SATR) - the measurement of chest deformity performed in a supine position with the use of a scoliometer (Orthopedic Systems Inc. OSI 1995). The scoliometer was set across the chest in the upper part of the sternum at the level of the 2nd-3rd rib (SATR Upper - SATRU) and in a lower part of the sternum (SATR lower - SATRL) (Fig. 1d) [28].

Pelvic Obliquity test (PO) - the measurement of pelvic obliquity was performed with the use of the scoliometer placed at the posterior superior iliac spines in a sitting position with supported lower limbs [28] (Fig. 1e). The measurement was performed in SMA II and SMA III individuals who were able to maintain a sitting position without assistance during the examination.

\section{Statistical analysis}

The results were analysed statistically with the use of IBM SPSS Statistics v.20 software. The means and standard deviations for CR, SATR and PO were calculated. Moreover, for each of the participants, the sum of CR left and CR right (cervical rotation sum - CRS) and the difference between CR left and CR right (cervical rotation difference - CRD) were calculated. The Shapiro Wilk test was used to assess normal distribution. In order to estimate differences between the groups the Mann-Whitney U test and the One - Way Anova were applied. When performing multiple post hoc comparisons, the Scheffe test was used, taking into account the correction for the number of comparisons performed. The Spearman correlation was used to analyse the correlation between CR, SATR, PO and Cobb angle values. The Pearson's chi square and Cramer's coefficient tests were applied as a measure of association between nominal variables of measurements and the occurrence of scoliosis in SMA patients. The level of significance was set at $p \leq 0.05$. The correlation strength was interpreted as follows: $<0.3$ negligible correlation, $0.3-0.5$ low positive (negative) correlation, $0.5-0.7$ moderate positive (negative) correlation, 0.7-0.9 high positive (negative) correlation, $>0.9$ - very high positive (negative) correlation [29].

\section{Results}

This study recruited 74 patients with types I, II, III SMA aged 2 to 18 (mean age $7.1 \pm 4.3$ years, weight $22.4 \pm$ $10.6 \mathrm{~kg}$, height $120.4 \pm 19.5 \mathrm{~cm}$, all SMA patients), including 40 girls and 34 boys. The group consisted of 21 individuals ( 9 girls and 12 boys) with type I SMA, 36 (21 girls and 15 boys) with type II SMA and 17 (10 girls and 7 boys) with type III SMA.

The study group included 21 participants who were unable to sit independently (21 SMA I), 44 nonambulant participants who were able to sit unsupported (36 SMA II, 8 SMA III) and 9 ambulant participants (SMA III). 
Thirty eight participants with SMA (51.4\%) used noninvasive ventilation, and 36 did not have respiratory support (48.6\%). Twenty six patients with SMA (35.1\%) declared that they did not use support standing, and 48 practiced support standing or walked (64.9\%).

The revealed incidence of scoliosis was 77\% (57 participants) in the SMA group. The incidence of scoliosis in SMA I group was $90 \%$, in SMA II - 83\% and in SMA III - 47\%. In 50 participants single scoliosis was observed (mean $32.4^{\circ} \pm 16.0$ ), while in 7 individuals double scoliosis occurred (thoracic mean $47.9^{\circ} \pm 20.1$, thoracic/lumbar mean $\left.59.1^{\circ} \pm 25.4\right)$.

The results were compared to the control group of 89 individuals, including 47 girls and 42 boys aged 2-18. The values of age, weight, height in SMA patients and the control group and information about scoliosis in SMA individuals are presented in Table 1.

\section{Cervical rotation (CR)}

The highest CR left, CR right and CRS values were noted in healthy participants, while the lowest values were observed in SMA I group (Table 1). The ranges of $\mathrm{CR}$ left and CR right were significantly bigger in the control group than in patients with SMA type I, II and III. The values of CR left and CR right did not differ between the SMA I, SMA II and SMA III groups (Table 2).

The value of CRS in the whole SMA group was approximately $20 \%$ lower than the value obtained in the control group. CRS was significantly smaller in all SMA subgroups compared to the groups of healthy individuals. The values obtained in SMA I, II and III groups did not differ significantly (Table 2).

The smallest differences between $\mathrm{CR}$ left and $\mathrm{CR}$ right were recorded in the control group. In 39 SMA participants, a difference of up to $5^{\circ}$ was noted between $C R$ left and CR right (CRD), while in 35 individuals $(47.2 \%)$ the difference was higher than $5^{\circ}$. Mean value of CRD in the whole SMA group differed significantly from the value in the control group $(p<$ 0.05). The largest CRD values were noted in the SMA I and SMA II groups. The value of CRD in these two groups was significantly higher than in the control group. No significant differences between SMA III and control group were observed. However, a significant difference was noted between SMA I group and participants with type II and III (Table 2).

Table 1 Mean values of age, weight, height, CR, SATR, PO measurements and Cobb angle in participants

\begin{tabular}{|c|c|c|c|c|}
\hline & $\begin{array}{l}\text { SMA I } \\
N=21\end{array}$ & $\begin{array}{l}\text { SMA II } \\
N=36\end{array}$ & $\begin{array}{l}\text { SMA III } \\
N=17\end{array}$ & $\begin{array}{l}\text { Control } \\
N=89\end{array}$ \\
\hline Age (years) $\pm S D$ & $6.5 \pm 5.0$ & 7.4. \pm 4.1 & $7.2 \pm 4.0$ & $6.8 \pm 3.7$ \\
\hline Weight $(\mathbf{k g}) \pm$ SD & $20.7 \pm 11.1$ & $23.7 \pm 10.6$ & $21.6 \pm 10.3$ & $26.0 \pm 13.4$ \\
\hline Height $(\mathrm{cm}) \pm$ SD & $116.6 \pm 22.9$ & $122.3 \pm 17.9$ & $121.1 \pm 18.9$ & $125.1 \pm 23.4$ \\
\hline CR left (o) $\pm S D$ & $20.4 \pm 10.7$ & $22.5 \pm 9.1$ & $24.5 \pm 9.4$ & $29.9 \pm 4.8$ \\
\hline Min / Max & $0.0 / 40.0$ & $0.0 / 36.0$ & $6.0 / 38.0$ & $18.0 / 40.0$ \\
\hline$C R$ right $(0) \pm S D$ & $21.9 \pm 10.8$ & $24.8 \pm 8.3$ & $23.9 \pm 9.3$ & $30.4 \pm 4.8$ \\
\hline Min / Max & $2.0 / 44.0$ & $5.0 / 40.0$ & $6.0 / 38.0$ & $20.0 / 42.0$ \\
\hline CRS (o) $\pm \mathrm{SD}$ & $42.3 \pm 14.4$ & $47.3 \pm 14.3$ & $48.4 \pm 17.4$ & $60.3 \pm 9.3$ \\
\hline Min / Max & $10.0 / 70.0$ & $5.0 / 76.0$ & $12.0 / 70.0$ & $40.0 / 82.0$ \\
\hline CRD (o) $\pm S D$ & $11.7 \pm 10.7$ & $6.9 \pm 7.6$ & $4.6 \pm 4.6$ & $2.0 \pm 1.9$ \\
\hline Min / Max & $0.0 / 38.0$ & $0.0 / 32.0$ & $0.0 / 11.0$ & $0.0 / 8.0$ \\
\hline SATRU (o) \pm SD & $6.3 \pm 3.8$ & $4.3 \pm 4.2$ & $2.4 \pm 1.7$ & $0.5 \pm 0.9$ \\
\hline Min / Max & $0.0 / 14.0$ & $0.0 / 15.0$ & $0.0 / 5.0$ & $0.0 / 3.0$ \\
\hline SATRL (o) \pm SD & $5.6 \pm 3.7$ & $5.1 \pm 4.0$ & $2.7 \pm 1.8$ & $0.3 \pm 0.6$ \\
\hline Min / Max & $0.0 / 15.0$ & $0.0 / 15.0$ & $0.0 / 7.0$ & $0.0 / 3.0$ \\
\hline $\mathrm{PO}(0) \pm \mathrm{SD}$ & NA & $8.7 \pm 6.4$ & $3.6 \pm 3.0$ & $0.8 \pm 1.0$ \\
\hline Min / Max & NA & $0.0 / 24.0$ & $0.0 / 10.0$ & $0.0 / 4.0$ \\
\hline $\begin{array}{l}\text { Single scoliosis } \\
\text { Cobb angle (o) }\end{array}$ & $\begin{array}{l}\text { ThL } 32.2 \pm 19.1 \\
N=17\end{array}$ & $\begin{array}{l}\text { ThL } 33.5 \pm 15.0 \\
N=25\end{array}$ & $\begin{array}{l}\text { ThL } 29.0 \pm 15.0 \\
N=8\end{array}$ & no scoliosis \\
\hline $\begin{array}{l}\text { Double scoliosis } \\
\text { Cobb angle (o) }\end{array}$ & $\begin{array}{l}\text { Th } 59.0 \pm 4.2 \\
\text { ThL } 51.0 \pm 29.1 \\
N=2\end{array}$ & $\begin{array}{l}\text { Th } 43.4 \pm 22.7 \\
\text { ThL } 62.4 \pm 26.5 \\
N=5\end{array}$ & no scoliosis & no scoliosis \\
\hline
\end{tabular}

Note: SMA I Spinal muscular atrophy type I, SMA II Spinal muscular atrophy type II, SMA III Spinal muscular atrophy type III, CR left Cervical rotation to the left, CR right Cervical rotation to the right, CRS Sum of CR left and CR right, $C R D$ Difference between CR left and CR right, SATRU Supine angle of trunk rotation upper; SATRL Supine angle of trunk rotation lower; PO Pelvic obliquity, NA Not analysed, SD Standard deviation, $\left({ }^{\circ}\right)$ Degrees, $N$ Number of participants, NA Not analyzed, Th Thoracic curve, ThL Thoracic/lumbar curve 
Table 2 Comparison of the CR, SATR and PO values obtained in SMA I, II, III and control groups

\begin{tabular}{llllllll}
\hline & CR left $\left(^{\circ}\right)$ & CR right $\left(^{\circ}\right)$ & CRS $\left(^{\circ}\right)$ & CRD $\left(^{\circ}\right)$ & SATRU $\left(^{\circ}\right)$ & SATRL $\left(^{\circ}\right)$ & PO $\left(^{\circ}\right)$ \\
\hline SMA I vs control & $\boldsymbol{p}=\mathbf{0 . 0 0 0 ^ { * }}$ & $\boldsymbol{p}=\mathbf{0 . 0 0 0 ^ { * }}$ & $\boldsymbol{p}=\mathbf{0 . 0 0 0 ^ { * }}$ & $\boldsymbol{p}=\mathbf{0 . 0 0 0 ^ { * }}$ & $\boldsymbol{p}=\mathbf{0 . 0 0 0 ^ { * }}$ & $\boldsymbol{p}=\mathbf{0 . 0 0 0 ^ { * }}$ & $\mathrm{NA}$ \\
SMA II vs control & $\boldsymbol{p}=\mathbf{0 . 0 0 0 ^ { * }}$ & $\boldsymbol{p}=\mathbf{0 . 0 0 1 ^ { * }}$ & $\boldsymbol{p}=\mathbf{0 . 0 0 0 ^ { * }}$ & $\boldsymbol{p}=\mathbf{0 . 0 0 0 ^ { * }}$ & $\boldsymbol{p}=\mathbf{0 . 0 0 0 ^ { * }}$ & $\boldsymbol{p}=\mathbf{0 . 0 0 0 ^ { * }}$ & $\boldsymbol{p}=\mathbf{0 . 0 0 0 ^ { * }}$ \\
SMA III vs control & $\boldsymbol{p}=\mathbf{0 . 0 4 4 ^ { * }}$ & $\boldsymbol{p}=\mathbf{0 . 0 0 9 ^ { * }}$ & $\boldsymbol{p}=\mathbf{0 . 0 0 3 ^ { * }}$ & $p=0.363$ & $p=0.172$ & $\boldsymbol{p}=\mathbf{0 . 0 2 1 ^ { * }}$ & $\boldsymbol{p}=\mathbf{0 . 0 1 1 ^ { * }}$ \\
SMA I vs SMA II & $p=0.855$ & $p=0.798$ & $p=0.723$ & $\boldsymbol{p}=\mathbf{0 . 0 2 5}$ & $p=0.672$ & $p=0.994$ & $\mathrm{NA}$ \\
SMA I vs SMA III & $p=0.512$ & $p=0.931$ & $p=0.631$ & $\boldsymbol{p}=\mathbf{0 . 0 0 2 ^ { * }}$ & $\boldsymbol{p}=\mathbf{0 . 0 0 3 ^ { * }}$ & $\boldsymbol{p}=\mathbf{0 . 0 2 3 ^ { * }}$ & $\mathrm{NA}$ \\
SMA II vs SMA III & $p=0.855$ & $\boldsymbol{p}=0.997$ & $\boldsymbol{p}=0.984$ & $p=0.559$ & $\boldsymbol{p}=\mathbf{0 . 0 2 6 ^ { * }}$ & $\boldsymbol{p}=\mathbf{0 . 0 0 4 ^ { * }}$ & $\boldsymbol{p}=\mathbf{0 . 0 0 0 *}$
\end{tabular}

Note: $C R$ Cervical rotation, $C R$ left Cervical rotation to the left, $C R$ right Cervical rotation to the right, CRS Sum of CR left and CR right, CRD Difference between CR left and CR right, SATR Supine angle of trunk rotation, SATRU Supine angle of trunk rotation upper, SATRL Supine angle of trunk rotation lower, PO Pelvic obliquity, SMA I Spinal muscular atrophy type I, SMA II Spinal muscular atrophy type II, SMA III Spinal muscular atrophy type III, NA Not analyzed, $\left(^{\circ}\right)$ Degrees, $\mathrm{p}$ - level of significance; * - significant difference

\section{Supine angle of trunk rotation (SATR)}

In the majority of SMA patients, chest asymmetry was noted. Only in the case of 7 children with SMA II and SMA III (9.5\% of the whole SMA group), the value of SATRU and SATRL measured with the scoliometer was $0^{\circ}$, while in the control group, a symmetrical chest was noted in 50 of the participants $(56.2 \%)$. The most severe deformities of the chest were observed in patients with SMA I and SMA II, while the smallest in patients with SMA 3.

The values of SATRU in the control group were significantly lower than the values obtained in SMA I and SMA II groups. The values of SATRL obtained by the healthy participants were significantly lower than the values noted in SMA I, SMA II and SMA III groups.

Differences between SMA I, SMA II and SMA III groups were significant, with the exception of SATRU in SMA I and SMA II groups (Table 2).

\section{Pelvic obliquity (PO)}

The PO test was performed on individuals with SMA II, SMA III and in the control group. All patients with SMA II and SMA III qualified for the tests were able to maintain the sitting position during the measurements. The lowest PO value was noted in controls, while the highest value was observed in patients with SMA II (Table 2). Pelvic obliquity occurred in 35 (97\%) patients with SMA II and in 15 participants with SMA III (88.2\%). The value of pelvic obliquity was higher than $4^{\circ}$ (the maximum PO value in the control group) in 24 (66.7\%) participants with type II SMA. Only 3 persons with SMA II and SMA III (5.6\%) had a symmetrical pelvis position $\left(0^{\circ}\right)$. In the case of 26 participants with SMA II and SMA III (49.1\%), pelvic obliquity ranged between $0^{\circ}$ and $4^{\circ}$, while in 27 patients (50.9\%) it was bigger than $4^{\circ}$. In the control group, a proper pelvis position was noted in 37 individuals $(56.1 \%)$. In the remaining participants, obliquity was between $1^{\circ}$ and $4^{\circ}$.

Pelvic obliquity was significantly higher in SMA II and SMA III groups than in the control group. Also, a significant difference in pelvic obliquity between SMA II and SMA III groups was noted (Table 2).

\section{CR, CRD, CRS, SATR and PO parameters in SMA group depending on age}

The analysis of the values of cervical rotation, chest deformity and pelvic obliquity revealed that CR left, CR right and CRS values decreases, while chest deformity and pelvic obliquity increase in participants older than 8 years. The highest CRD and PO values were noted in participants above 11 years (Fig. 2).

\section{CR, SATR, PO values in SMA patients with scoliosis and without scoliosis}

In 57 SMA participants with scoliosis, chest deformity (SATRU: Cramer's V $=0.619, p=0.000$; SATRL: Cramer's $\mathrm{V}=0.678, p=0.000)$ and oblique pelvic position (Cramer's V $=0.811, p=0.000$ ) were significantly more frequent than in the subgroup without scoliosis (17 participants).

The analysis showed significant differences between CRleft, CRS, SATRU, SATRL and PO values obtained by SMA patients with scoliosis and without scoliosis. No differences between CRright and CRD were observed (Fig. 3).

\section{Correlations between CRD, CRS, SATR, PO and cobb angle in SMA groups}

Due to differences in motor capabilities, the correlations between the parameters CR, SATR, PO and Cobb angle were tested separately in SMAI, SMA II and SMA III groups.

A significant low correlation between Cobb angle and CRD in the SMA I group was found. As the scoliosis angle increased, the difference between the cervical rotation ranges increased. In addition, a moderate relationship between SATRL and CRD was observed in this group. A low positive correlation relationship between chest asymmetry and CRD was found in the SMA II group, but it was not observed in the SMA III patients (Table 3). 
Cervical Rotation left (CR left)

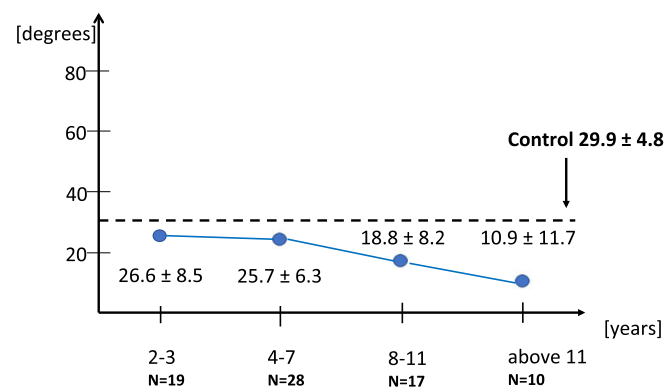

Cervical Rotation Sum (CRS)

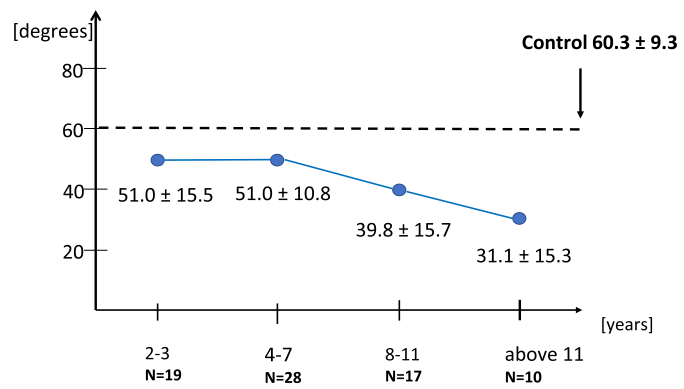

Supine Angle of Trunk Rotation Upper (SATRU)

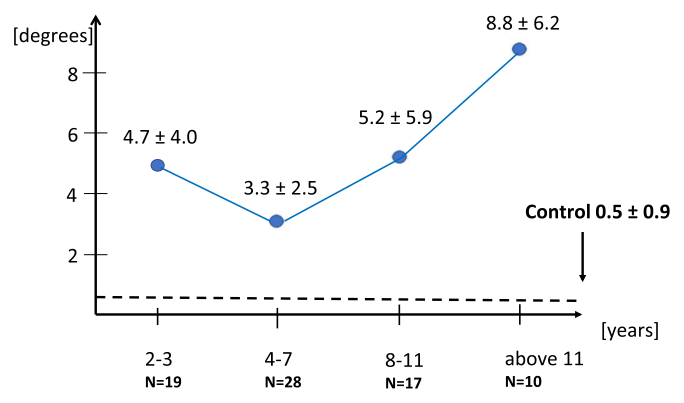

Cervical Rotation right (CR right)

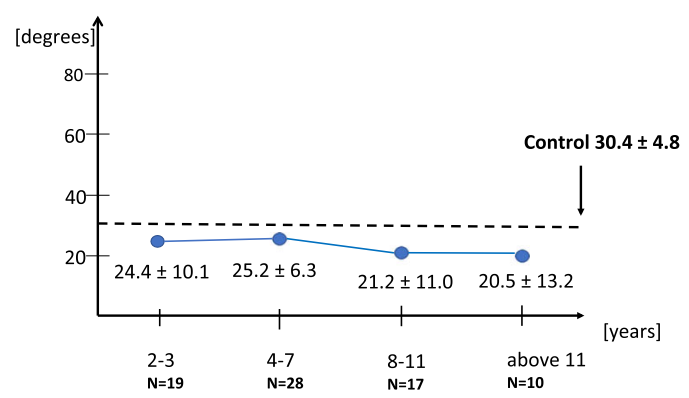

Cervical Rotation Difference (CRD)

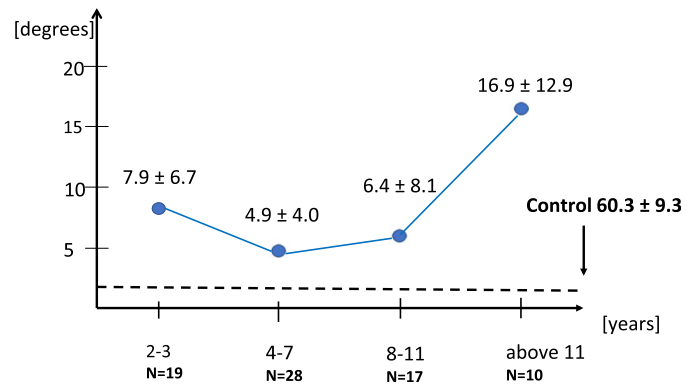

Supine Angle of Trunk Rotation Lower (SATRL)

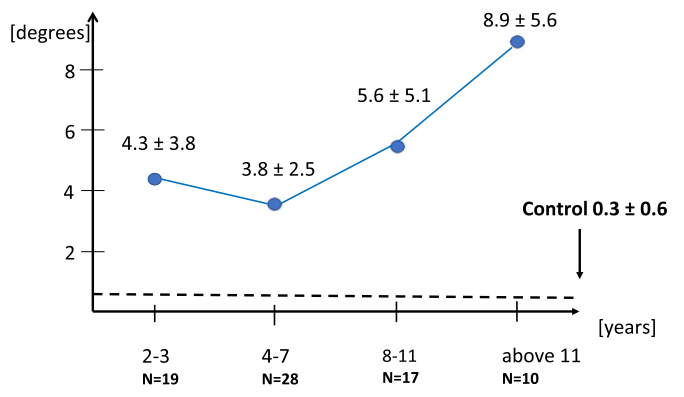

Pelvic obliquity (PO)

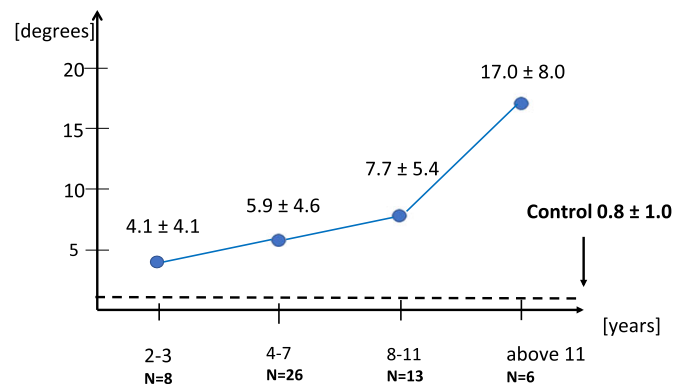

Fig. 2 Variability of CR, SATR and PO tests values depending on age in the SMA group. Note: SMA - spinal muscular atrophy; (o) - degrees 


\section{CR, SATR and PO values in SMA individuals with scoliosis and without scoliosis}

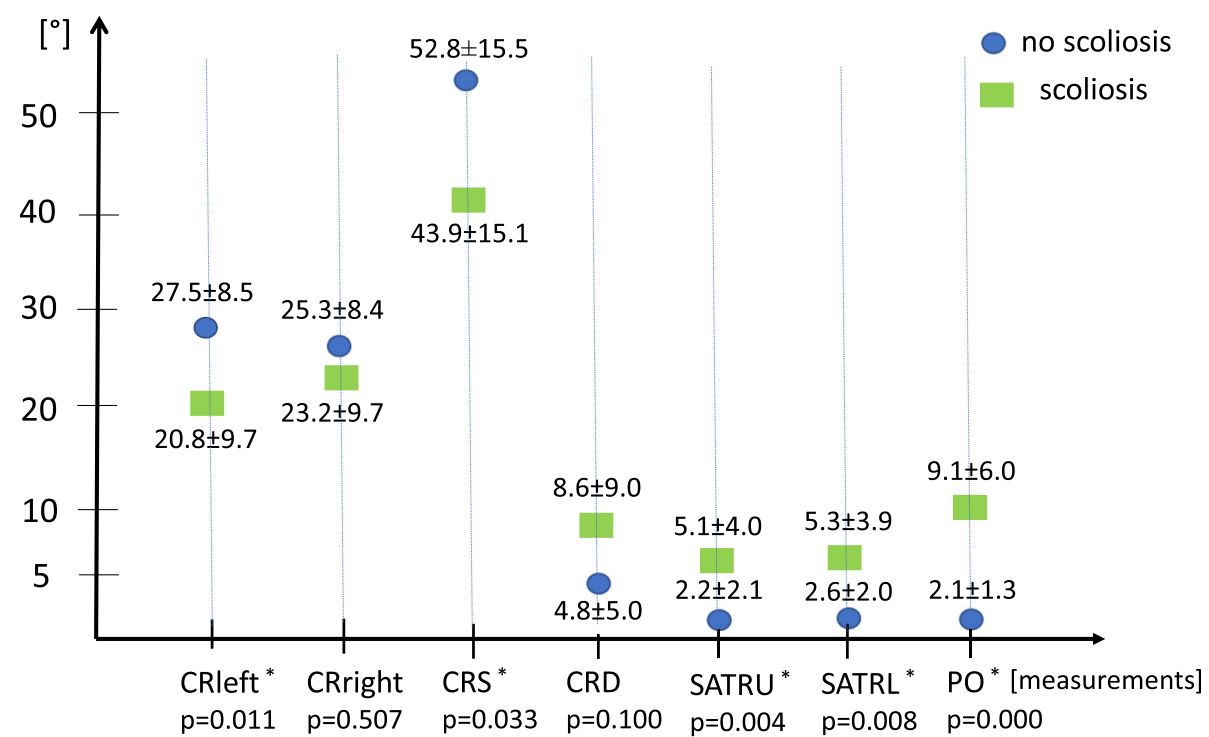

Fig. 3 Comparison of CR, SATR and PO values in SMA individuals with scoliosis and without scoliosis. Note: CR - cervical rotation; CR left cervical rotation to the left; $C R$ right - cervical rotation to the right; $C R S$ - sum of CR left and CR right; CRD - difference between CR left and CR right; SATR - supine angle of trunk rotation; SATRU - supine angle of trunk rotation upper; SATRL - supine angle of trunk rotation lower; PO pelvic obliquity; SMA - spinal muscular atrophy; (o) - degrees; $\mathrm{p}$ - level of significance; * - significant difference

The analysis showed a high correlation between Cobb angle and PO in SMA II group. Larger Cobb angle values corresponded to larger pelvic tilt values. There was no such association in SMA III group. PO measurements in SMA II group were also positively low correlated with CRD, SATRU and SATRL values. An moderate positive correlations between PO, CRleft and CRS parameters were observed in SMA III participants (Table 3).

\section{Scoliosis, non-invasive ventilation and support standing in SMA group}

There was no significant relationship between the incidence of scoliosis and the use of non-invasive ventilation (V-Cramer coefficient $=0.082, p=0.482)$. The comparison of the mean values of the Cobb angle in the participants using non-invasive ventilation (mean Cobb 27,4 $4^{\circ}$ and not using ventilatory support (mean Cobb $45,2^{\circ}$ ) showed no significant differences $(p=0.076)$. The analysis of postural parameters indicated no significant differences between the values of CRleft $(p=0.080)$, CRD $(p=0.636)$, SATRU $(p=0.615)$, SATRL $(p=0.563)$ and PO $(p=0.369)$. In the ventilated patients, significantly higher values of CRright $(p=0.050)$ and CRS $(p=0.020)$ were found.

Low but statistically significant strength of the relationship between the incidence of scoliosis and support standing/ walking (V-Cramer coefficient $=0.335, p=$
0.004) was noticed. Scoliosis occurred in $96.2 \%$ of people who did not declare spending their time standing. In the group of people who reported supported standing or walking, scoliosis occurred in $43.2 \%$.

The participants who reported standing or walking presented less severe deformities of the upper chest SATRU $(p=0.043)$. The higher values of cervical rotation CRleft $(p=0.002)$, CRright $(p=0.004)$ and CRS $(p=0.001)$ were also observed in this group. There was no difference between the of SATRL $(p=0.068)$, CRD $(p=0.175)$ and $\mathrm{PO}(p=0.084)$ parameters.

\section{Discussion}

Spine and chest deformities may affect the functional state of individuals with neuromuscular diseases [13, 20, $21,30]$. Therefore, the international recommendations for diagnosis and management of SMA recognize the importance of a regular physical examination, with a focus on the musculoskeletal system. It is recommended that the physical examination should include, inter alia, assessment of the spine alignment, range of motions, muscle strength, motor functions and the quality of daily activities [22]. The assessment of young children enables early detection of deformities and implementation of appropriate interventions.

In our study it was revealed that there exist significant differences in cervical rotation, chest shape and pelvis 
Table 3 Correlations between CR, SATR, PO and Cobb angle values in SMAI, SMA II and SMA III groups

\begin{tabular}{|c|c|c|c|c|c|c|c|c|}
\hline \multicolumn{9}{|c|}{ SMA I $(N=21)$} \\
\hline & CRleft & CRright & CRS & CRD & SATRU & SATRL & PO & Cobb $(N=19)$ \\
\hline $\begin{array}{l}\text { CRleft } \\
\text { p }\end{array}$ & NA & $\begin{array}{l}-.059 \\
.801\end{array}$ & $\begin{array}{l}.686^{\mathrm{a}} \\
.001\end{array}$ & $\begin{array}{l}-.216 \\
.346\end{array}$ & $\begin{array}{l}-.086 \\
.710\end{array}$ & $\begin{array}{l}-.162 \\
.482\end{array}$ & NA & $\begin{array}{l}-.440 \\
.059\end{array}$ \\
\hline $\begin{array}{l}\text { CRright } \\
\text { p }\end{array}$ & $\begin{array}{l}-.059 \\
.801\end{array}$ & NA & $\begin{array}{l}.628^{\mathrm{a}} \\
.002\end{array}$ & $\begin{array}{l}-.083 \\
.720\end{array}$ & $\begin{array}{l}-.106 \\
.647\end{array}$ & $\begin{array}{l}-.207 \\
.368\end{array}$ & NA & $\begin{array}{l}.031 \\
.900\end{array}$ \\
\hline $\begin{array}{l}\text { CRS } \\
p\end{array}$ & $\begin{array}{l}.686^{\mathrm{a}} \\
.001\end{array}$ & $\begin{array}{l}.628^{\mathrm{a}} \\
.002\end{array}$ & NA & $\begin{array}{l}-.188 \\
.414\end{array}$ & $\begin{array}{l}-.161 \\
.486\end{array}$ & $\begin{array}{l}-.281 \\
.218\end{array}$ & NA & $\begin{array}{l}-.290 \\
.229\end{array}$ \\
\hline $\begin{array}{l}\text { CRD } \\
p\end{array}$ & $\begin{array}{l}-.216 \\
.346\end{array}$ & $\begin{array}{l}-.083 \\
.720\end{array}$ & $\begin{array}{l}-.188 \\
.414\end{array}$ & NA & $\begin{array}{l}.282 \\
.215\end{array}$ & $\begin{array}{l}.514^{\mathrm{a}} \\
.017\end{array}$ & NA & $\begin{array}{l}.460^{\mathrm{a}} \\
.048\end{array}$ \\
\hline $\begin{array}{l}\text { SATRU } \\
\mathrm{p}\end{array}$ & $\begin{array}{l}-.086 \\
.710\end{array}$ & $\begin{array}{l}-.106 \\
.647\end{array}$ & $\begin{array}{l}-.161 \\
.486\end{array}$ & $\begin{array}{l}.282 \\
.215\end{array}$ & NA & $\begin{array}{l}.389 \\
.081\end{array}$ & NA & $\begin{array}{l}.248 \\
.307\end{array}$ \\
\hline $\begin{array}{l}\text { SATRL } \\
\mathrm{p}\end{array}$ & $\begin{array}{l}-.162 \\
.482\end{array}$ & $\begin{array}{l}-.207 \\
.368\end{array}$ & $\begin{array}{l}-.281 \\
.218\end{array}$ & $\begin{array}{l}.514^{\mathrm{a}} \\
.017\end{array}$ & $\begin{array}{l}.389 \\
.081\end{array}$ & NA & NA & $\begin{array}{l}.360 \\
.130\end{array}$ \\
\hline PO & NA & NA & NA & NA & NA & NA & NA & NA \\
\hline $\begin{array}{l}\text { Cobb } \\
\text { p }\end{array}$ & $\begin{array}{l}-.440 \\
.059\end{array}$ & $\begin{array}{l}.031 \\
.900\end{array}$ & $\begin{array}{l}-.290 \\
.229\end{array}$ & $\begin{array}{l}.460^{a} \\
.048\end{array}$ & $\begin{array}{l}.248 \\
.307\end{array}$ & $\begin{array}{l}.360 \\
.130\end{array}$ & NA & NA \\
\hline \multicolumn{9}{|c|}{ SMA II $(N=36)$} \\
\hline & CRleft & CRright & CRS & CRD & SATRU & SATRL & PO & Cobb $(N=30)$ \\
\hline $\begin{array}{l}\text { CRleft } \\
\mathrm{p}\end{array}$ & NA & $\begin{array}{l}.304 \\
.071\end{array}$ & $\begin{array}{l}.830^{\mathrm{a}} \\
.000\end{array}$ & $\begin{array}{l}.033 \\
.848\end{array}$ & $\begin{array}{l}-.010 \\
.953\end{array}$ & $\begin{array}{l}.116 \\
.502\end{array}$ & $\begin{array}{l}-.177 \\
.301\end{array}$ & $\begin{array}{l}-.310 \\
.095\end{array}$ \\
\hline $\begin{array}{l}\text { CRright } \\
\text { p }\end{array}$ & $\begin{array}{l}.304 \\
.071\end{array}$ & NA & $\begin{array}{l}.729^{a} \\
.000\end{array}$ & $\begin{array}{l}.284 \\
.093\end{array}$ & $\begin{array}{l}.234 \\
.170\end{array}$ & $\begin{array}{l}.128 \\
.456\end{array}$ & $\begin{array}{l}.217 \\
.203\end{array}$ & $\begin{array}{l}-.196 \\
.299\end{array}$ \\
\hline $\begin{array}{l}\text { CRS } \\
\mathrm{p}\end{array}$ & $\begin{array}{l}.830^{\mathrm{a}} \\
.000\end{array}$ & $\begin{array}{l}.729^{a} \\
.000\end{array}$ & NA & $\begin{array}{l}.142 \\
.408\end{array}$ & $\begin{array}{l}.031 \\
.857\end{array}$ & $\begin{array}{l}.065 \\
.705\end{array}$ & $\begin{array}{l}-.044 \\
.799\end{array}$ & $\begin{array}{l}-.335 \\
.070\end{array}$ \\
\hline $\begin{array}{l}\text { CRD } \\
p\end{array}$ & $\begin{array}{l}.033 \\
.848\end{array}$ & $\begin{array}{l}.284 \\
.093\end{array}$ & $\begin{array}{l}.142 \\
.408\end{array}$ & NA & $\begin{array}{l}.445^{\mathrm{a}} \\
.006\end{array}$ & $\begin{array}{l}.494^{\mathrm{a}} \\
.002\end{array}$ & $\begin{array}{l}.416^{\mathrm{a}} \\
.012\end{array}$ & $\begin{array}{l}.257 \\
.171\end{array}$ \\
\hline $\begin{array}{l}\text { SATRU } \\
\mathrm{p}\end{array}$ & $\begin{array}{l}-.010 \\
.953\end{array}$ & $\begin{array}{l}.234 \\
.170\end{array}$ & $\begin{array}{l}.031 \\
.857\end{array}$ & $\begin{array}{l}.445^{\mathrm{a}} \\
.006\end{array}$ & NA & $\begin{array}{l}.578^{\mathrm{a}} \\
.000\end{array}$ & $\begin{array}{l}.391^{\mathrm{a}} \\
.018\end{array}$ & $\begin{array}{l}.321 \\
.084\end{array}$ \\
\hline $\begin{array}{l}\text { SATRL } \\
\text { P }\end{array}$ & $\begin{array}{l}.116 \\
.502\end{array}$ & $\begin{array}{l}.128 \\
.456\end{array}$ & $\begin{array}{l}.065 \\
.705\end{array}$ & $\begin{array}{l}.494^{\mathrm{a}} \\
.002\end{array}$ & $\begin{array}{l}.578^{\mathrm{a}} \\
.000\end{array}$ & NA & $\begin{array}{l}.464^{\mathrm{a}} \\
.004\end{array}$ & $\begin{array}{l}.404^{\mathrm{a}} \\
.027\end{array}$ \\
\hline $\begin{array}{l}\mathrm{PO} \\
\mathrm{p}\end{array}$ & $\begin{array}{l}-.177 \\
.301\end{array}$ & $\begin{array}{l}.217 \\
.203\end{array}$ & $\begin{array}{l}-.044 \\
.799\end{array}$ & $\begin{array}{l}.416^{\mathrm{a}} \\
.012\end{array}$ & $\begin{array}{l}.391^{\mathrm{a}} \\
.018\end{array}$ & $\begin{array}{l}.464^{\mathrm{a}} \\
.004\end{array}$ & NA & $\begin{array}{l}.703^{\mathrm{a}} \\
.000\end{array}$ \\
\hline $\begin{array}{l}\text { Cobb } \\
p\end{array}$ & $\begin{array}{l}-.310 \\
.095\end{array}$ & $\begin{array}{l}-.196 \\
.299\end{array}$ & $\begin{array}{l}-.335 \\
.070\end{array}$ & $\begin{array}{l}.257 \\
.171\end{array}$ & $\begin{array}{l}.321 \\
.084\end{array}$ & $\begin{array}{l}.404^{\mathrm{a}} \\
.027\end{array}$ & $\begin{array}{l}.703^{\mathrm{a}} \\
.000\end{array}$ & NA \\
\hline \multicolumn{9}{|c|}{ SMA III $(N=17)$} \\
\hline & CRleft & CRright & CRS & CRD & SATRU & SATRL & PO & Cobb $(N=8)$ \\
\hline $\begin{array}{l}\text { CRleft } \\
\mathrm{p}\end{array}$ & NA & $\begin{array}{l}.713^{\mathrm{a}} \\
.001\end{array}$ & $\begin{array}{l}.928^{\mathrm{a}} \\
.000\end{array}$ & $\begin{array}{l}.402 \\
.110\end{array}$ & $\begin{array}{l}.038 \\
.884\end{array}$ & $\begin{array}{l}-.155 \\
.552\end{array}$ & $\begin{array}{l}-.655^{\mathrm{a}} \\
.004\end{array}$ & $\begin{array}{l}-.313 \\
.451\end{array}$ \\
\hline $\begin{array}{l}\text { CRright } \\
\text { p }\end{array}$ & $\begin{array}{l}.713^{\mathrm{a}} \\
.001\end{array}$ & NA & $\begin{array}{l}.907^{\mathrm{a}} \\
.000\end{array}$ & $\begin{array}{l}.408 \\
.104\end{array}$ & $\begin{array}{l}-.037 \\
.887\end{array}$ & $\begin{array}{l}-.131 \\
.618\end{array}$ & $\begin{array}{l}-.243 \\
.346\end{array}$ & $\begin{array}{l}.042 \\
.921\end{array}$ \\
\hline $\begin{array}{l}\text { CRS } \\
p\end{array}$ & $\begin{array}{l}.928^{\mathrm{a}} \\
.000\end{array}$ & $\begin{array}{l}.907^{\mathrm{a}} \\
.000\end{array}$ & NA & $\begin{array}{l}.371 \\
.143\end{array}$ & $\begin{array}{l}-.059 \\
.821\end{array}$ & $\begin{array}{l}-.197 \\
.449\end{array}$ & $\begin{array}{l}-.509^{a} \\
.037\end{array}$ & $\begin{array}{l}-.024 \\
.955\end{array}$ \\
\hline $\begin{array}{l}\text { CRD } \\
p\end{array}$ & $\begin{array}{l}.402 \\
.110\end{array}$ & $\begin{array}{l}.408 \\
.104\end{array}$ & $\begin{array}{l}.371 \\
.143\end{array}$ & NA & $\begin{array}{l}.265 \\
.304\end{array}$ & $\begin{array}{l}.142 \\
.588\end{array}$ & $\begin{array}{l}-.077 \\
.770\end{array}$ & $\begin{array}{l}.307 \\
.459\end{array}$ \\
\hline $\begin{array}{l}\text { SATRU } \\
\text { p }\end{array}$ & $\begin{array}{l}.038 \\
.884\end{array}$ & $\begin{array}{l}-.037 \\
.887\end{array}$ & $\begin{array}{l}-.059 \\
.821\end{array}$ & $\begin{array}{l}.265 \\
.304\end{array}$ & NA & $\begin{array}{l}.189 \\
.467\end{array}$ & $\begin{array}{l}.075 \\
.776\end{array}$ & $\begin{array}{l}.123 \\
.772\end{array}$ \\
\hline $\begin{array}{l}\text { SATRL } \\
\mathrm{p}\end{array}$ & $\begin{array}{l}-.155 \\
.552\end{array}$ & $\begin{array}{l}-.131 \\
.618\end{array}$ & $\begin{array}{l}-.197 \\
.449\end{array}$ & $\begin{array}{l}.142 \\
.588\end{array}$ & $\begin{array}{l}.189 \\
.467\end{array}$ & NA & $\begin{array}{l}.051 \\
.847\end{array}$ & $\begin{array}{l}-.111 \\
.793\end{array}$ \\
\hline $\begin{array}{l}\mathrm{PO} \\
\mathrm{p}\end{array}$ & $\begin{array}{l}-.655^{\mathrm{a}} \\
.004\end{array}$ & $\begin{array}{l}-.243 \\
.346\end{array}$ & $\begin{array}{l}-.509^{a} \\
.037\end{array}$ & $\begin{array}{l}-.077 \\
.770\end{array}$ & $\begin{array}{l}.075 \\
.776\end{array}$ & $\begin{array}{l}.051 \\
.847\end{array}$ & NA & $\begin{array}{l}.457 \\
.255\end{array}$ \\
\hline $\begin{array}{l}\text { Cobb } \\
p\end{array}$ & $\begin{array}{l}-.313 \\
.451\end{array}$ & $\begin{array}{l}.042 \\
.921\end{array}$ & $\begin{array}{l}-.024 \\
.955\end{array}$ & $\begin{array}{l}.307 \\
.459\end{array}$ & $\begin{array}{l}.123 \\
.772\end{array}$ & $\begin{array}{l}-.111 \\
.793\end{array}$ & $\begin{array}{l}.457 \\
.255\end{array}$ & NA \\
\hline
\end{tabular}

Note: $C R$ Cervical rotation, $C R$ left Cervical rotation to the left, $C R$ right Cervical rotation to the right, $C R S$ Sum of CR left and CR right, CRD Difference between CR left and CR right, SATR Supine angle of trunk rotation, SATRU Supine angle of trunk rotation upper, SATRL Supine angle of trunk rotation lower, PO Pelvic obliquity, SMA I Spinal muscular atrophy type I, SMA II Spinal muscular atrophy type II, SMA III Spinal muscular atrophy type III, $N$ Number of participants, NA Not analyzed, $\left({ }^{\circ}\right)$ Degrees; ${ }^{\text {a }}$ - significant correlation 
position while sitting between SMA patients and healthy individuals.

It was observed that CR in SMA patients is limited compared to healthy individuals. Differences between the ranges of rotation to the left and to the right in SMA I and SMA II groups were significantly higher than in the control group. In the SMA I group, a significant positive correlation between CRD and Cobb's angle was found. This means that in children and adolescents with higher values of Cobb angle, the difference between the ranges of left and right cervical rotation increased. We have not found any studies on cervical rotation in SMA patients. Previous studies examined only contractures of the upper and lower extremities $[14,15]$ and their impact on limitations in daily activities [31]. Salazar et al. found that minimal hip and knee joint contractures in patients with SMA types II and III were associated with diminished motor ability [31].

Difficulties in everyday functioning resulting from an improper head position, often related to scoliosis, are also rarely mentioned [20]. Some authors drew attention to a potential correlation between head position, body position and swallowing [11, 21]. The biggest limitation of the range of rotation in the cervical spine weas observed by us among the oldest participants. This restriction may be related to swallowing difficulties that occur in people with SMA, but this phenomenon requires further study. The important goals for rehabilitation in SMA patients is to prevent contractures and maintain function and mobility [22]. Therefore, it is worth introducing neck stretching exercises into therapy.

In our study the SATR test revealed that chest deformities in SMA patients occurred more often and were significantly severe than in the healthy individuals. The highest values of SATR were noted in individuals with SMA I and SMA II who most often experienced breathing difficulties and need non-invasive ventilatory support [32-34]. In the case of patients with SMA III, the test revealed significantly lower values of chest deformities compared to SMA I and SMA II participants. The abnormal, bell-shaped chest in patients with SMA types I and II was found in studies conducted with the use of the 3D opto-electronic plethysmography. SMA III patients participating in this study showed an almost rectangular ribcage shape [35].

One of the factors that can affect breathing in people with neuromuscular diseases is scoliosis [36]. A significant correlation between the severity of scoliosis and the percentage of predicted vital capacity and peak flow was found in SMA patients in previous studies [9]. The weakness of respiratory muscles and chest deformity, usually related to scoliosis, have been recognized as the main causes of breathing disorders [8-10, 12, 13]. The study by Fujak et al. [12] revealed that among 4-6-year- old patients with SMA type II, there was a distinct reduction in the relative vital capacity, while in SMA III patients relative vital capacity values were higher. Differences in the shape of the chest in the SMA subgroups demonstrated in our study may affect respiratory parameters, but this hypothesis needs to be confirmed in the future.

We found that pelvic obliquity in patients with SMA was significantly severe than in the control group. Moreover, the values of pelvic obliquity was higher in SMA II than in SMA III group. It has been highlighted in the literature that scoliosis and improper pelvis position constitute the main problems in orthopaedic treatment of the majority of SMA patients $[13,17]$. On the basis of radiological images, Fujak et al. concluded that pelvic obliquity in a sitting position occurred in the majority of SMA II patients, regardless of age, i.e. even in children aged $0-4$ years. They also noted that both scoliosis and pelvic obliquity increased in older participants and is more severe in SMA II than in SMA III patients [13]. Our observations confirm these results. Pelvic obliquity was observed in the majority of SMA II patients. In addition, the strongest correlations between $\mathrm{PO}$ and Cobb angle were observed in the this group. An asymmetrical pelvic position was found in $92 \%$ children with SMA II and SMA III aged 2-4 years. The obliquity of the pelvis increased in older participants.

The results obtained by us confirmed that age has a significant impact on the progression of skeletal deformities and limitations of range of motion. The values of cervical rotation, chest deformity and pelvic obliquity were worse in older children. Deterioration of these parameters was observed in children over 7 years of age. Gradual progression of impairments in the musculoskeletal system may hypothetically affect negative changes of motor functions assessed by functional scales, that are observed especially in no-ambulant patients during the growth [37].

This study has another practical application due to the fact that it sought correlations between disorders located in various parts of the body in SMA patients. A significant correlations between the cervical rotation parameters, chest asymmetry and pelvic obliquity were found in the SMA subgroups. It suggests the need for constant monitoring of the cervical spine range of rotation, chest structure and the pelvic position in these patients.

The analysis carried out in SMA participants with scoliosis and without scoliosis showed significant differences between these groups. CR, SATR and PO measurements showed more severe disorders in SMA patients with scoliosis. In addition, a significant correlation was observed between the Cobb angle and CRD values in participants with the type SMAI, Cobb angle and thoracic deformity measurements, and pelvic 
obliquity in the SMA2 group. It indicates the relationship between the severity of scoliosis and the analyzed postural parameters in children, who were unable to walk. Therefore non-sitters and sitters should be carefully monitored, as also suggested by other authors [7, 37].

Higher values of the ranges of cervical rotation were found in individuals who reported using non-invasive ventilation and support standing/walking. Participants using support standing systems or walkers showed smaller deformation in the upper part of the chest. These preliminary observations confirm the accuracy of the recommendations regarding rehabilitation [22] and require further observation in larger groups of participants.

The presented study has some limitations. This project did not take into account the functional status of the participants. In the future, it is worth to analyze the correlation between the size of scoliosis, postural parameters and motor function assessed with validated scales.

This study has shown that CR, SATR and PO tests provide relevant information about body posture in SMA patients. Tests are easy to apply, safe and enable early detection of changes in the musculoskeletal system. The results indicate that there is a need to implement interventions aimed at increasing the range of cervical rotation, correction of the chest or positioning in patients with SMA. Measurements could be applied in the treatment process as an addition to the X-ray image, especially in patients currently being treated pharmacologically and to evaluate different therapeutic interventions.

A multidisciplinary approach is fundamental principle in the management of SMA patients [22]. The spine surgeons responsible for the treatment of neuromuscular scoliosis often have a significant impact on the overall treatment. The collected data and results entitle us to offer some suggestions for the spine surgeons and other specialists involved in the treatment of a child with SMA with coexisting musculoskeletal disorders. Due to the observed correlations between the severity of scoliosis, ranges of cervical rotation, chest deformity and pelvic oblique position, it is important to evaluate various structures of the musculoskeletal system and their functions while examining a person with SMA. Patients with SMA and coexisting musculoskeletal disorders or scoliosis should be referred to physiotherapists and other specialists who can implement stretching exercises, proper positioning, bracing or respiratory stimulation. Support standing and no-invasive ventilation have a positive effect on the shaping of the chest and cervical rotation. Non-ambulant patients should be monitored carefully and regularly.

\section{Conclusions}

The results of the study suggest that Cervical Rotation (CR), Supine Angle of Trunk Rotation (SATR) and
Pelvic Obliquity (PO) tests may assist in the assessment of SMA patients in addition to the radiographic evaluation of the spine. Biomechanical relationships between disorders located in various skeletal structures should be taken into account in the treatment of SMA patients. Special attention should be given to assessing postural parameters in non- sitters and sitters. Treatment of patients with SMA and associated musculoskeletal disorders requires a multi-specialist approach.

\begin{abstract}
Abbreviations
SMA: Spinal muscular atrophy; CR: Cervical Rotation test; CR left: Cervical rotation to the left; $C R$ right: Cervical rotation to the right; CRS: Sum of CR left and CR right; CRD: Difference between CR left and CR right; SATR: Supine Angle of Trunk Rotation test; SATRU: Supine Angle of Trunk Rotation Upper test; SATRL: Supine Angle of Trunk Rotation Lower test; PO: Pelvic Obliquity test
\end{abstract}

\section{Acknowledgements}

We are thankful to the SMA Foundation Poland for cooperation and all patients who participated in the study.

\section{Authors' contributions \\ AS study design, literature research, clinical examination of the participants, supervision of statistical analysis, manuscript writing; ŁM, KG clinical examination of the participants, collecting data, literature research; WR preparation of databases, statistical analysis; MJ critical assessment of the integrity of the entire study and manuscript. The authors approved the final manuscript.}

\section{Funding}

The costs of translation was supported by the Ministry of Science and Higher Education in 2017 as a research project of Józef Piłsudski University of Physical Education in Warsaw [DS-258].

\section{Availability of data and materials}

Available from the corresponding author if requested (please contact orthosas@wp.pl).

\section{Ethics approval and consent to participate}

The study was accepted by the Senate Research Ethics Committee at University of Physical Education in Warsaw (SKE 01-03/2016). The protocol was explained to all participants. The legal guardians of the participants gave their written consent to participate in the study. The patients' data were regarded as confidential.

\section{Consent for publication}

We confirm that the informed consent form has been signed by guardians of the participants.

\section{Competing interests}

The authors declare that they have no competing interests.

\section{Author details \\ ${ }^{1}$ Faculty of Rehabilitation, Józef Piłsudski University of Physical Education, Marymoncka 34, 00-968 Warsaw, Poland. 22nd Department of Neurology, Institute of Psychiatry and Neurology, Warsaw, Poland. ${ }^{3}$ Center of Functional Rehabilitation ORTHOS, Warsaw, Poland. ${ }^{4}$ Rare Diseases Research Platform, Mossakowski Medical Research Centre, Polish Academy of Sciences, \\ Pawińskiego 5, 02-106 Warsaw, Poland.}

Received: 19 May 2020 Accepted: 12 October 2020

Published online: 07 November 2020

\section{References}

1. Lefebvre S, Buirglen L, Reboullet S, Clermont O, Burlet P, Viollet L, et al. Identification and characterization of a spinal muscular atrophy-determining gene. Cell. 1995;80:155-65. 
2. D'Amico A, Mercuri E, Tiziano FD, Bertini E. Spinal muscular atrophy. Orphanet J Rare Dis. 2011;6:71.

3. lannaccone ST, Russman BS, Browne RH, Buncher R, White M, Samaha FJ. Prospective analysis of strength in spinal muscular atrophy. J Child Neurol. 2000;15:97-101.

4. Kroksmark AK, Beckung E, Tulinius M. Muscle strength and motor function in children and adolescents with spinal muscular atrophy II and III. Eur J Ped Neurol. 2001:5:191-8.

5. Kaufmann P, McDermott MP, Darras BT, Finkel RS, Sproule DM, Kang PB, et al. Prospective cohort study of spinal muscular atrophy types 2 and 3 . Neurology. 2012;79(18):1889-97.

6. Munsat TL, Davies KE, International SMA Consortium meeting. 26-28 June 1992, Bonn, Germany. Neuromuscul Disord. 1992;2(5-6):423-8.

7. Mercuri E, Bertini E, lannaccone ST. Childhood spinal muscular atrophy: controversies and challenges. Lancet Neurol. 2012:11(5):443-52.

8. Wang $\mathrm{CH}$, Finkel RS, Bertini ES, Schroth M, Simonds A, Wong B, et al. Consensus statement for standard of care in spinal muscular atrophy. J Child Neurol. 2007;22:1027-49.

9. Robinson D, Galasko CS, Delaney C, Williamson JB, Barrie JL. Scoliosis and lung function in spinal muscular atrophy. Eur Spine J. 1995;4:268-73.

10. Chng SY, Wong YQ, Hui JH, Wong HK, Ong HT, Goh DY. Pulmonary function and scoliosis in children with spinal muscular atrophy types II and III. J Paediatr Child Health. 2003:39:673-6.

11. van den Engel-Hoek L, Erasmus CE, van Bruggen HW, de Swart BJ, Sie LT, Steenks $\mathrm{MH}$, et al. Dysphagia in spinal muscular atrophy type II: more than a bulbar problem? Neurology. 2009;73(21):1787-91.

12. Fujak A, Raab W, Schuh A, Kreß A, Forst R, Forst J. Operative treatment of scoliosis in proximal spinal muscular atrophy: results of 41 patients. Arch Orthop Trauma Surg. 2012;132(12):1697-706.

13. Fujak A, Raab W, Schuh A, Richter S, Forst R, Forst J. Natural course of scoliosis in proximal spinal muscular atrophy type II and Illa: descriptive clinical study with retrospective data collection of 126 patients. BMC Musculoskelet Disord. 2013;14:283.

14. Wang HY, Ju YH, Chen SM, Lo SK, Jong YJ. Joint range of motion limitations in children and young adults with spinal muscular atrophy. Arch Phys Med Rehabil. 2004:85(10):1689-93.

15. Fujak A, Kopschina C, Gras F, Forst R, Forst J. Contractures of the upper extremities in spinal muscular atrophy type II. Descriptive clinical study with retrospective data collection. Ortop Traumatol Rehabil. 2010;12:410-9.

16. Negrini S, Donzelli S, Aulisa AG, Czaprowski D, Schreiber S, de Mauroy JC, et al. 2016 SOSORT guidelines: Orthopaedic and rehabilitation treatment of idiopathic scoliosis during growth. Scoliosis Spinal Disord. 2018;13:3.

17. Granata C, Merlini L, Magni E, Marini ML, Stagni SB. Spinal muscular atrophy: natural history and orthopaedic treatment of scoliosis. Spine. 1989:14:760-2.

18. Rodillo E, Marini ML, Heckmatt JZ, Dubowitz V. Scoliosis in spinal muscular atrophy: review of 63 cases. J Child Neurol. 1989;4:118-23.

19. Kouwenhoven JW, Van Ommeren PM, Pruijs HE, Castelein RM. Spinal decompensation in neuromuscular disease. Spine. 2006;31:188-91.

20. Mullender MG, Blom NA, De Kleuver M, Fock JM, Hitters WM, Horemans AM, et al. A Dutch guideline for the treatment of scoliosis in neuromuscular disorders. Scoliosis. 2008;3:14

21. van den Engel-Hoek L, de Swart BJ, Erasmus CE, de Groot IJ. Is head balance a major determinant for swallowing problems in patients with spinal muscular atrophy type 2? J Child Neurol. 2008;23(8):919-21.

22. Mercuri E, Finkel RS, Muntoni F, Wirth B, Montes J, Main M, et al. Diagnosis and management of spinal muscular atrophy: part 1: recommendations for diagnosis, rehabilitation, orthopedic and nutritional care. Neuromuscul Disord. 2018;28(2):103-5

23. Chiriboga CA. Nusinersen for the treatment of spinal muscular atrophy. Expert Rev Neurother. 2017;17(10):955-62.

24. Maharshi V, Hasan S. Nusinersen: the first option beyond supportive care for spinal muscular atrophy. Clin Drug Investig. 2017;37(9):807-17.

25. Birnkrant DJ, Bushby K, Bann CM, Alman BA, Apkon SD, Blackwell A, et al. Diagnosis and management of Duchenne muscular dystrophy, part 2: respiratory, cardiac, bone health, and orthopaedic management. Lancet Neurol. 2018;17(4):347-61.

26. Bunnell WP. An objective criterion for scoliosis screening. J Bone Joint Surg Am. 1984;66(9):1381-7.

27. Negrini S, Aulisa AG, Aulisa L, Circo AB, de Mauroy JC, Durmala J, et al. 2011 SOSORT quidelines: Orthopaedic and rehabilitation treatment of idiopathic scoliosis during growth. Scoliosis. 2012;7:3.
28. Stępień A, Jędrzejowska M, Guzek K, Rekowski W, Stępowska J. Reliability of four tests to assess body posture and the range of selected movements in individuals with spinal muscular atrophy. BMC Musculoskelet Disord. 2019; 20:54.

29. Mukaka MM. Statistics corner: a guide to appropriate use of correlation coefficient in medical research. Malawi Med J. 2012;24(3):69-71.

30. Roberts SB, Tsirikos Al. Factors influencing the evaluation and management of neuromuscular scoliosis: a review of the literature. J Back Musculoskelet Rehabil. 2016:29(4):613-23.

31. Salazar R, Montes J, Dunaway Young S, McDermott MP, Martens W, Pasternak A, et al. Quantitative evaluation of lower extremity joint contractures in spinal muscular atrophy: implications for motor function. Pediatr Phys Ther. 2018;30(3):209-15.

32. Bach JR, Tuccio MC, Khan U, Saporito LR. Vital capacity in spinal muscular atrophy. Am J Phys Med Rehabil. 2012:91(6):487-93.

33. Bach JR. POINT: is noninvasive ventilation always the Most appropriate manner of long-term ventilation for infants with spinal muscular atrophy type 1? Yes, almost always. Chest. 2017;151(5):962-5.

34. Pane M, Palermo C, Messina S, Sansone VA, Bruno C, Catteruccia M, et al. An observational study of functional abilities in infants, children, and adults with type 1 SMA. Neurology. 2018;91(8):696-703.

35. LoMauro A, Banfi P, Mastella C, Alberti K, Baranello G, Aliverti A. A new method for measuring bell-shaped chest induced by impaired ribcage muscles in spinal muscular atrophy children. Front Neurol. 2018;9: 703Published 2018 Sep 13. https://doi.org/10.3389/fneur.2018.00703.

36. Hull J, Aniapravan R, Chan E, Chatwin M, Forton J, Gallagher J, et al. British Thoracic Society guideline for respiratory management of children with neuromuscular weakness. Thorax. 2012;67:1-40. https://doi.org/10.1136/ thoraxjnl-2012-201964

37. Mercuri E, Finkel R, Montes J, Mazzone ES, Sormani MP, Main M, et al. Patterns of disease progression in type 2 and 3 SMA: implications for clinical trials. Neuromuscul Disord. 2016;26(2):126-31.

\section{Publisher's Note}

Springer Nature remains neutral with regard to jurisdictional claims in published maps and institutional affiliations.

Ready to submit your research? Choose BMC and benefit from:

- fast, convenient online submission

- thorough peer review by experienced researchers in your field

- rapid publication on acceptance

- support for research data, including large and complex data types

- gold Open Access which fosters wider collaboration and increased citations

- maximum visibility for your research: over $100 \mathrm{M}$ website views per year

At $\mathrm{BMC}$, research is always in progress.

Learn more biomedcentral.com/submissions 